\title{
Food Sanitation Knowledge, Attitude, and Behavior for the University Restaurants Employees
}

\author{
Wen-Hwa Ko \\ Department of Restaurant, Hotel and Institutional Management, Fu-Jen University, Chinese Taipei. \\ Email: 073770@mail.fju.edu.tw
}

Received June $9^{\text {th }}, 2011$; revised July 21 $1^{\text {st }}, 2011$; accepted July $28^{\text {th }}, 2011$.

\begin{abstract}
The purpose of this study was to discuss the food sanitation knowledge, attitude, and behavior for the employees of university restaurants, and furthermore, to explain the interrelations of these various were occurring at school. A questionnaire survey procedure was used. Each two constructs of food sanitation attitude and behavior were analyzed by factor analysis. Data was analyzed by description, Pearson's correlation and multiple regression analysis. The correctness rate toward the whole sanitation knowledge of trials was 70\%. The overall attitude toward food sanitation was prone to positive and the attitude of employee self-responsibility was superior to the attitude of food sanitation practice. The sanitary guiding behavior was better than the sanitary habit behavior; and there was a significant relationship indicated through Pearson correlation analysis among three various. The sanitation knowledge and sanitation attitude showed a $42.6 \%$ predictive power to behavior, the attitude was mediated between knowledge and behavior. The university restaurant employees shared a more pessimistic view toward the benefits of training and the institutions could establish a committee for monitoring food nutrition and sanitation. It provides valuable information for development employees training while seeking to raise school restaurant food safety levels.
\end{abstract}

Keywords: Food Sanitation, Knowledge, Attitude, Behavior

\section{Introduction}

School meals must provide the organism with all the necessary nutrients and be safe from the hygienic-sanitary point of view. Beside their quests for knowledge, learning and finding the right places on campus to satisfy their physical hungers is a prerequisite to college students [1]. Chen [2] studied the impact of collective behavior on college students' eat-out preferences; he found that the majority of college students had allowances to spend on food. Students were able to afford their preferential meals in restaurants based on what they liked. Huang [3] was the only one relevant study that was identified as special interest and investigated and explored the university restaurant catering employees' views held on food sanitation based on their knowledge, attitude, and behavior toward food sanitation. However, this study was lagging behind the legislative requirements announced in 2000 by the Department of Health of Executive Yuan for Good Hygienic Practice (GHP). All catering premises were governed to practice by the GHP after the year 2000. There is a great need to update academic studies to coincide to the level of the current legislative requirement imposed by the Department of Health [4]. The statistics show that $15 \%-20 \%$ of food poisonings were occurring at school; the primary mode of the poisonings were caused by a lack of temperature control of food and cross contamination in Taiwan, 2008 [5]. Poor sanitary practices of food storage, handling, and preparation can create an environment in which contaminations are more easily transmitted [6]. Proper personal and food handling practices are the basis for preventing the transmission of pathogens from food handling personnel to the consumer [7]. The retail food service industry has intensified efforts to improve retail food safety through the training of restaurant employees $[8,9]$. The food poisoning outbreaks reveal that small and medium established sized businesses are often important locations in the transmission of food borne illnesses [10].

Schwardtz [11] suggested four types of relationships between knowledge, attitude, and behavior. The first type 
of relationship exists where knowledge can directly influence attitude but not directly influence behavior. The second type of relationship exists where knowledge and attitude influence each other at the same time. The third type of relationship exists where knowledge and attitude independently influence behavior. The fourth type of relationship exists where knowledge shared direct and indirect influences on behavior. Attitude was the mediating variable between knowledge and behavior. A number of studies [12,13] have indicated that although training may bring about an increased knowledge of food safety, this does not always result in a positive change in food handling behavior. It has been suggested that this disparity between knowledge and practice occurs because of much of the existing training. Rennie [14] showed that the KAP model assumes that an individual's behavior or practice $(\mathrm{P})$ is dependent on their knowledge $(\mathrm{K})$ and suggested that the mere provision of information will lead directly to a change in attitude (A) and consequently a change in behavior. It has been suggested that this model is flawed in its assumption that knowledge is the main precursor to behavioral change [15]. Lin and Chen [16] found when studying school children's knowledge, attitude, and behavior toward food sanitation in Taiwan that these factors interacted with each other in a positive manner. Huang [17] found that lunch-box factory employees' knowledge, attitude, and behavior toward food sanitation in Taiwan were in a positive relationship with each other. These results also found that knowledge and attitude were not positively influenced and knowledge and behavior also did not share a positive relationship. In conclusion, of the previous findings on the four types of relationships between knowledge, attitude, and behavior toward food sanitation, they were inconclusive with inconsistent findings that demonstrated the precise relationships shared between these three factors. Therefore, we will attempt to find the relationship between food sanitation knowledge, attitude, and behavior.

The purpose of this study centered on the investigation of the knowledge, attitude, and behavior of employees of university restaurants in Taipei, whereby the relationships of these factors with their determinant influences were also explored. It is hoped that such a study would adequately provide the industries and governmental agencies with blueprints for future employee training, and references for policy purposes. It shall also act as guiding indexes for selecting future university restaurants in tenders.

\section{Methodology}

\subsection{Sampling of Participants}

A quota-sampling method was adopted for data collec- tion. The subjects were full and part time catering employees from university and college restaurants located in Taipei, Taiwan. The pre-testing of surveys was conducted in Fu Jen Catholic University's campus restaurant in November 2009. Fifty-seven questionnaires were returned. The formal run of the survey was conducted in December 2009. Two groups of random subjects were selected from 5 universities in Taipei City, and five universities in Taipei County among 45 universities from both districts. Questionnaires were given out in the designated universities' restaurants to catering employees such as food preparers, food distributors, food packaging employees, and restaurant employees. Both part-time and full-time employees were included. There were a total of 550 questionnaires given out with 493 returned, resulting in a return rate of $89.6 \%$.

\subsection{Questionnaire Development}

There were four parts to the questionnaires. The first part of the questionnaire included personal background variables such as gender, age, work experience, education, certification of cooking licenses, participation in food sanitation trainings, and whether the subject was under supervision or not. The second part of the questionnaire included 20 yes/no questions on their knowledge of food sanitation. The set of questions were in reference to the knowledge base form suggested from studies conducted by Huang [3], and the exam questions for $\mathrm{C}$ level Chinese cuisine chef certification. With each right answer, 1 mark was allocated to the subject. No mark would be given for wrong answers. The more knowledgeable the subject was, the greater the marks. Questions were focused on two central themes that related to good standard hygiene practice and food poisoning issues. The third and forth parts of the questionnaires focused on food sanitation attitudes and behaviors in reference to the studies conducted by Lee et al. [18] and Tokuc et al. [9]. There were 15 questions in each part using a 5-point Likert Scale. The greater marks the subject rendered the higher the rank they obtained, which indicated good food sanitation behavior.

\subsection{Factor Analysis, Reliability and Validity Analysis}

The returned pre-test questionnaires were analyzed by factor analysis of maximum likelihood factor extraction on the attitude part. After rotation, the constructs number was 2, factor loading was greater than 0.3 , and KMO value was $0.730(P<0.05)$. Based on these analyses, question 7 and question 8 were eliminated. The rest of the questions were divided into two constructs. The first construct consisted of item numbers $1,2,3,5,6,10$, and 14. It was called the "employee's self-responsibility atti- 
tude”. The second construct consisted of item numbers 4 , $9,11,12,13$, and 15 . It was called the "food sanitation practice attitude". The cronbach's $\alpha$ value for "employee's self-responsibility attitude" was 0.742 , and the cronbach's $\alpha$ value for the "food sanitation practice attitude" was 0.843 . For the behavior part, the questionnaire also used the maximum likelihood factor extraction and rotation, factor loading was greater than 0.3 , and KMO value was $0.697(P<0.05)$, therefore, question 5 was eliminated. The rest of the questions were constructed into two constructs based on variable value. The first construct consisted of questions $2,4,7,8,11,12,14$, and 15 , it was called the "food sanitation guiding behavior". The second construct consisted of numbers $1,3,6,9,10$, and 13, it was called the "sanitary habit behavior". These two constructs could be interpreted as $33.63 \%$. After conducting reliability analysis, the sanitary guiding behavior had a cronbach's $\alpha$ value of 0.703 , whereas "sanitary guiding behavior” had a cronbach's $\alpha$ value of 0.747 . The questionnaire surveyed on the attitude produced cronbach's $\alpha$ values for employee self-responsibility attitude and food sanitation practice attitude as 0.723 , and 0.9 . The cronbach's $\alpha$ value for sanitary guiding behavior and sanitary habit behavior was 0.800 and 0.734 . The design of this study also utilized expert validity analysis to gain insights to contribute to the finalized formal questionnaire, which was completed in January 2008 by five experts in relative fields.

\subsection{Data Analysis}

This study used the SPSS 17.0 version of statistic software to conduct data analysis. The data analysis methodologies were in line with the aim and design of this study, which included descriptive covariance analysis, factor analysis, reliability analysis, correlation analysis, and multiple regression analysis.

\section{Results}

Of the 473 respondents, most of them were female (60.0\%). The age group peaked at 25 to 29 years, which accounted for $25.8 \%$. Nearly fifty percent of the respondents had worked in the related industry for 1 to 3 years. In respect to their educational background, $44.2 \%$ were high school/technical school graduates. In respect to their participation in food sanitation trainings, $78.2 \%$ of all subjects had not had any training within a year. Most subjects had responsible employee supervision of food sanitation in their work places. Other related results are shown in Table 1.

A greater proportion of catering employees answered correctly the part that involved good hygiene practice sanitation (GHP) standard ( $\mathrm{M}=7.63)$. Whereas questions involving food poisoning had lower counts of correct
Table 1. The socio-demographic characteristics for the restaurant employees $(\mathrm{N}=473)$.

\begin{tabular}{|c|c|c|c|}
\hline Characteristics & Description item & $\mathrm{n}$ & Percents (\%) \\
\hline Gender & Male & 189 & 40.0 \\
\hline \multirow{8}{*}{ Age } & Female & 284 & 60.0 \\
\hline & Under 19 & 103 & 22.2 \\
\hline & $20-24$ & 86 & 18.5 \\
\hline & $25-29$ & 122 & 25.8 \\
\hline & $30-34$ & 55 & 11.8 \\
\hline & $35-39$ & 57 & 12.1 \\
\hline & $45-49$ & 36 & 7.6 \\
\hline & Above 50 & 13 & 2.7 \\
\hline \multirow{6}{*}{$\begin{array}{l}\text { Work experience } \\
\text { (years) }\end{array}$} & Under 1 & 117 & 24.7 \\
\hline & $1-3$ & 213 & 45.0 \\
\hline & $4-6$ & 37 & 7.8 \\
\hline & $7-9$ & 35 & 7.4 \\
\hline & $10-12$ & 47 & 9.9 \\
\hline & Above 13 & 24 & 5.1 \\
\hline \multirow[t]{5}{*}{ Education } & Under junior high school & 14 & 3.0 \\
\hline & Junior high school & 36 & 7.6 \\
\hline & Senior high school & 209 & 44.2 \\
\hline & College & 37 & 7.8 \\
\hline & University and above & 177 & 37.4 \\
\hline \multirow[t]{2}{*}{ Cooking licenses } & No & 335 & 70.8 \\
\hline & Yes & 138 & 29.2 \\
\hline \multirow[t]{2}{*}{ Training class } & No & 370 & 78.2 \\
\hline & Yes & 103 & 21.8 \\
\hline \multirow{2}{*}{$\begin{array}{l}\text { Whether or not the } \\
\text { subject was under } \\
\text { supervision }\end{array}$} & Yes & 332 & 70.2 \\
\hline & No & 141 & 29.8 \\
\hline
\end{tabular}

answers $(M=6.99)$. Within the expected GHP standard, $99.6 \%$ of the subjects knew that, "Disinfected water proof gloves should be worn on hands for processing uncooked- ready-to-eat foods.” This item had the highest number of correct answers. The least correctly answered question pertained to "Freezing had a better sterilizing effect than heating." Only $14.0 \%$ of the employees answered it correctly. With respect to food poisoning, the most correct item (99.8\%) was, "Lunch boxes that were not sold during lunch time can be kept until night time for reselling." The question that was answered the least correctly was "Salmonella was easily contracted from seafood products," with only a $28.8 \%$ correct rate. It was demonstrated that most restaurant employees were not familiar enough with food poisoning agents and the types of food poisoning.

There were two constructs involved in the catering employee's food sanitation attitudes, which were "employee's self-responsibility attitude" and "food sanitation practice attitude" as shown in Table 2. The average mean for "employee's self-responsibility attitude" was 4.42, and the average mean for "food sanitation practice attitude" was 4.48 . This demonstrated that the majority 
Table 2. The scaling of sanitation attitudes for the employee $(\mathrm{N}=473)$.

\begin{tabular}{|c|c|c|c|c|}
\hline Constructs & Item & Mean & S.D. & Ranking \\
\hline Employee’s & 1. I think it is very important to study more food hygiene knowledge. & 4.47 & 0.631 & 5 \\
\hline \multirow{6}{*}{$\begin{array}{l}\text { self-responsibility } \\
\text { attitude }\end{array}$} & 2. It is my responsibility to offer safe hygienic foods to customers. & 4.58 & 0.547 & 4 \\
\hline & $\begin{array}{l}\text { 3. I think hand washing before touching food can decrease the risk of } \\
\text { contamination. }\end{array}$ & 4.67 & 0.479 & 1 \\
\hline & $\begin{array}{l}\text { 5. I think disinfected water proof gloves could decrease food poison- } \\
\text { ing. }\end{array}$ & 4.60 & 0.670 & 3 \\
\hline & 6. Wine can get rid of the fishy smell. & 4.61 & 0.683 & 2 \\
\hline & $\begin{array}{l}\text { 10. I think only the food processing handling person should be in } \\
\text { charge of decreasing the risk of food poising. }\end{array}$ & 4.27 & 1.016 & 6 \\
\hline & 14. Participating in food sanitation training is very important to me. & 3.74 & 1.215 & 7 \\
\hline Mean & & 4.42 & & \\
\hline \multirow{6}{*}{$\begin{array}{l}\text { Food sanitation } \\
\text { practice attitude }\end{array}$} & 4. I think raw and cooked foods must be handled separately. & 4.67 & 0.520 & 1 \\
\hline & $\begin{array}{l}\text { 9. I think chefs should participate in food sanitation seminars each } \\
\text { year. }\end{array}$ & 4.23 & 0.791 & 6 \\
\hline & $\begin{array}{l}\text { 11. I think reading more periodicals pertaining to hygiene are impor- } \\
\text { tant. }\end{array}$ & 4.45 & 0.703 & 4 \\
\hline & 12. Taking hygiene classes will improve my hygiene habits. & 4.43 & 0.641 & 5 \\
\hline & 13. It is my responsibility to correctly execute GHP. & 4.48 & 0.631 & 3 \\
\hline & $\begin{array}{l}\text { 15. I think it is very important for the employee to have proper hygi- } \\
\text { enic habits. }\end{array}$ & 4.59 & 0.545 & 2 \\
\hline Mean & & 4.48 & & \\
\hline
\end{tabular}

of restaurants' catering employees had positive attitudes toward food sanitation. Among those items such as, "I think hand washing before touching food can decrease the risk of contamination," and "I think raw food and cooked food must be handled separately," had the highest scores. However, with respect to participation in food sanitation training there were different results, where answers to the questions, "To participate in food sanitation seminars is very important to me," and "I think chefs should participate in a food sanitation seminar each year," had lower scores for employee self-responsibility attitude.

Table 3 shows the two constructs involved in the catering employee's food sanitation behavior, which was "sanitary guiding behavior" and "sanitary habit behavior". For "sanitary guiding behavior" the average was 4.03. For "sanitary habit behavior" the average was 4.29 . Among these items in the construct of food sanitation

Table 3. The scaling of sanitation behavior for the employee $(N=473)$.

\begin{tabular}{|c|c|c|c|c|}
\hline Constructs & Item & Mean & S.D. & Ranking \\
\hline Sanitary guiding & 2. I will wear the tidy uniform prior to beginning work. & 4.23 & 1.004 & 3 \\
\hline \multirow[t]{7}{*}{ behavior } & 4. I will perform at least one health check every year. & 3.53 & 1.342 & 7 \\
\hline & 7. If I have wounds on my hand, I will wear gloves. & 4.55 & 0.738 & 1 \\
\hline & $\begin{array}{l}\text { 8. I will use different chopping blocks to deal with the food } \\
\text { materials. }\end{array}$ & 3.97 & 1.157 & 5 \\
\hline & $\begin{array}{l}\text { 11. I will completely disinfect the cutter and chopping block } \\
\text { after work every day. }\end{array}$ & 4.12 & 0.984 & 4 \\
\hline & 12. I will clean and dry the facility after work everyday. & 4.54 & 0.703 & 2 \\
\hline & 14. When I wash the dishes, I will use the three sinks methods. & 3.79 & 1.248 & 6 \\
\hline & 15. I need to clean the drainage every day. & 3.51 & 1.423 & 8 \\
\hline Mean & & 4.03 & & \\
\hline \multirow[t]{6}{*}{$\begin{array}{l}\text { Sanitary habit } \\
\text { behavior }\end{array}$} & $\begin{array}{l}\text { 1. The first thing to do upon entering the kitchen is wash my } \\
\text { hands. }\end{array}$ & 4.62 & 0.633 & 1 \\
\hline & 3. I will wash my hands when I touch the cooked food. & 4.51 & 0.779 & 3 \\
\hline & 6. I don’t use cooking tools to taste the food. & 4.10 & 1.314 & 5 \\
\hline & 9. I will dispose of any moldy food. & 4.57 & 0.878 & 2 \\
\hline & 10. If there are cracks on the dishes, I will not to use them. & 3.67 & 1.485 & 6 \\
\hline & 13. I will disinfect the work area regularly. & 4.24 & 0.906 & 4 \\
\hline Mean & & 4.29 & & \\
\hline
\end{tabular}


guiding behavior, "I would do at least one health check each year," "I did not need to clean the drainage each day," "When I washed the dishes, I would use the three sinks method," and "If there were cracks on the dishes I would still use them," were not over 4 point scales (Table 3).

As shown in Table 4, there were positive relationships between knowledge, attitude, and behavior on food sanitation extrapolated from these university and college restaurants catering employees. Further, food sanitation attitude and food sanitation behavior were positively related. These findings correlate with the findings reported by Chen [2].

As shown in Table 5, there were significant influences between food sanitation knowledge and attitude, the entire $\mathrm{R}^{2}$ was 0.025 , indicating that food sanitation knowledge could be interpreted into $2.5 \%$ of food sanitation attitudes. Between the influences of food sanitation knowledge and behavior, food sanitation knowledge could be interpreted into $6.4 \%$ of food sanitation behavior. However, food sanitation knowledge and attitude can be explained by $42.6 \%$ of food sanitation behavior. In this study, the independent variable (knowledge) affected the mediator (attitude) in the first equation; in the second equation, the independent variable (knowledge) affected the dependent variable (behavior) while the mediator (attitude) also affected the dependent variable (behavior). In the third equation the dependent variable regressed on both the independent variable and the mediator. According to our results, food sanitation attitude was a partial mediated effect of behavior. Compared to Table 5, it was also found that the Beta coefficient for knowledge on behavior had shown a decreased trend that indicated attitude was the partial mediator variable for knowledge on behavior. This matched the findings reported by Schwartz [11] where the fourth type of interaction, in which knowledge had a direct or indirect relationship on behavior, and attitude was the mediating variable between knowledge and behavior. It could be stipulated that knowledge, attitude, and behavior were associated with one another. Under two knowledge constructs of "good hygiene practice knowledge" and "food poisoning know- ledge" together with the two constructs of "employee self-responsibility attitude" and "food sanitation practice attitude" from food sanitation attitude had significant influences on three aspects from food sanitation behavior other than the aspects of "food poisoning", "Good hygiene practice knowledge", "employee self-responsibility attitude" and "food sanitation practice attitude", which could explain $44.9 \%$ of food sanitation behavior (Table 6).

\section{Discussion \& Recommendation}

\subsection{Discussion}

In this study, it was found that knowledge of good hygiene practices scored better than knowledge of food poisoning. The area of food poisoning agents' transmission channels was lacking. However, with respect to participation in food sanitation training there were different results where answers to the questions. It indicates that most catering employees thought food sanitation training was not important. Special attention should be rendered to address this problem. Training catering employees elevated their sanitation knowledge. In particular, training is a good way to increase food poisoning knowledge. Food sanitation attitudes had an average score of between 3.74 and 4.67, where the attitude of the group as a whole inclined toward being more positive. Food sanitation behavior had an average score of between 3.57 and 4.57. For "sanitary guiding behavior" the average was 4.03 and "sanitary habit behavior" the average was 4.29.

From the analysis of relationships between knowledge, attitude, and behavior were extrapolated and found that they shared positive relationships with one another. The results also indicated attitude was the mediating variable for knowledge on behavior. Griffith and Clayton [19]

Table 4. The relationship among knowledge, attitude, and behavior for employees.

\begin{tabular}{cccc}
\hline & Knowledge & Attitude & Behavior \\
\hline Knowledge & 1 & & \\
Attitude & $0.163^{*}$ & 1 & \\
Behavior & $0.263^{*}$ & $0.636^{*}$ & 1 \\
\hline
\end{tabular}

Table 5. Regression analysis of food safety knowledge, attitude, and behavior for employees.

\begin{tabular}{|c|c|c|c|c|}
\hline Dependent variable - Independent variable & Adjusted $\mathrm{R}^{2}$ & Standardized Beta Coefficient & $t$ Value & Significance \\
\hline Attitude - knowledge & 0.025 & 0.163 & 3.592 & $0.000^{*}$ \\
\hline Behavior- knowledge & 0.064 & 0.256 & 5.757 & $0.000^{*}$ \\
\hline Behavior- attitude & 0.403 & 0.636 & 18.870 & $0.000^{*}$ \\
\hline Behavior & 0.426 & & & \\
\hline - knowledge & & 0.162 & 4.517 & $0.000^{*}$ \\
\hline - attitude & & 0.609 & 17.011 & $0.000^{*}$ \\
\hline
\end{tabular}

${ }^{*} P<0.05$. 
Table 6. Regression analysis of food safety knowledge construct and attitude construct to behavior for employees.

\begin{tabular}{|c|c|c|c|c|}
\hline $\begin{array}{l}\text { Independent } \\
\text { variable }\end{array}$ & $\begin{array}{l}\text { Adjusted } \\
\qquad R^{2}\end{array}$ & $\begin{array}{c}\text { Standardized } \\
\text { Beta Coefficient }\end{array}$ & $t$ Value & $\begin{array}{l}\text { Signifi- } \\
\text { cance }\end{array}$ \\
\hline & 0.449 & & & \\
\hline $\begin{array}{c}\text { Good hygiene } \\
\text { practice knowledge }\end{array}$ & & 0.190 & 5.362 & $0.000^{*}$ \\
\hline $\begin{array}{l}\text { Food poisoning } \\
\text { knowledge }\end{array}$ & & 0.040 & 1.173 & 0.242 \\
\hline $\begin{array}{c}\text { Employee } \\
\text { self-responsibility } \\
\text { attitude }\end{array}$ & & 0.127 & 2.450 & $0.015^{*}$ \\
\hline $\begin{array}{l}\text { Food sanitation } \\
\text { practice attitude }\end{array}$ & & 0.506 & 9.615 & $0.000^{*}$ \\
\hline
\end{tabular}

reported that improved knowledge will lead to behavioral changes involving improved practices, and also suggested that other factors, including staff attitudes, can limit or prevent improvements in staff practices. Training for employees has been shown to improve food safety knowledge and hygienic awareness and may result in improved food safety practices [20], however, there is considerable evidence that improved knowledge does not always translate into improved food handling behavior [21]. Thus, there would appear to be a clear linkage between effective formal training, improved catering practices, and prevention or significant reduction of food borne outbreaks in the foodservice industry. Attitudes, an important factor besides knowledge and enforcement, ensure a downward trend of food borne illnesses. The necessary link of positive behavior, attitudes, and continued education of food handlers towards the sustainability of safe food handling practices has been highlighted [12]. The studies [13] have demonstrated that although training may increase food safety knowledge, a positive change does not always subsequently occur in terms of food handling behavior.

\subsection{Recommendation}

The university catering employees shared a more pessimistic view toward the benefits of training. It is suggested that the academic institution should take a more serious role in implementing more training programs to improve its employees' knowledge and attitude toward food sanitation. Through the cascades of intrinsic learning processes it was understood that knowledge transformed attitude where attitude further influenced behavior. Thus, nothing should be more important than to improve employees' knowledge through training where a more positive attitude can be formed that fortifies the desired food sanitation behavior. Additionally, institu- tions could establish a student committee for monitoring food nutrition and sanitation. Some schools have already implemented student committees for monitoring in campus restaurants. Although the responsibility of overseeing campus restaurants usually lies within the realm of the institution dietician, getting the students involved will facilitate a better emphasis and understanding for these students. Finally, institutions could increase the number of food poisoning courses, although most employees had an understanding of the legislation of good hygienic practices, but this study indicated that a lack of food poisoning knowledge was apparent. It is suggested that improvement can be seen through implementing food poisoning courses while providing sound supervision will indeed rectify this insufficiency. For the recommendation of future research, it would be helpful to conduct comparisons of the differences between on campus and off campus restaurants catering employees' knowledge, attitude, and behavior toward food sanitation. Interviews can be facilitated to probe the owner's concerns over challenges and problems faced in their business operation and how they intend to resolve these problems. It is also helpful to compare the differences between franchised chain restaurants and independent restaurants.

\section{REFERENCES}

[1] A. K. C. Campos, A. M. S. Cardonha, L. B. G. Pinheiro, N. R. Ferreira, P. R. M. Azevedo and T. L. M. Stamford, "Assessment of Personal Hygiene and Practices of Food Handlers in Municipal Public Schools of Natal, Brazil,” Food Control, Vol. 2 ,No. 10, 2009, pp. 807-810. doi:10.1016/j.foodcont.2008.10.010

[2] N. Y. Chen, "The Study of the Effects on Conformity for Purchasing Decision of Food Away-from-Home of College Students," Unpublished Master Degree Thesis, Shih Hsin University, Taipei, 2004.

[3] S. Y. Huang, "A Study of F and B Employees' Food Sanitation Behavior in Different Counties,” Journal of Health Education, Vol. 15, No.1, 1994, pp. 15-20.

[4] Department of Health, "Good Hygiene Practice," Department of Health, Executive Yuan, ROC, Taipei, Taiwan, 2005.

[5] Department of Health, "Information of Food News,” 2010. http://food.doh.gov.tw/FoodNew/MenuThird.aspx?SecondMenuID=34\&ThirdMenuID=298

[6] J. E. Fielding, A. Aguirre and E. Palaiologos, "Effectiveness of Altered Incentives in a Food Safety Inspection Program," Prevent Medicine, Vol. 32, No. 3, 2001, pp. 239-244. doi:10.1006/pmed.2000.0796

[7] H. S. Evans, P. Madden, C. Doudlas, G. K. Adak, S. J. O’Brien, T. Djuretic, P. G. Wall and R. Stanwell-Smith, "General Outbreaks of Infectious Intestinal Disease in England and Wales: 1995 and 1996," Community Disease Public Health, Vol. 1, No. 2, 1998, pp. 165-171. 
[8] R. Lynch, B. I. Elledge, C. C. Griffith and D. T. Boatrigh, “A Comparison of Food Safety Knowledge among Restaurant Managers, by Source of Training and Experience, in Oklahoma County, Oklahoma," Journal of Environment Health, Vol. 66, No. 1, 2003, pp. 9-14.

[9] B. Tokuc, G. Ekuklu, U. Berberoglu, E. Bilge and H. Dedeler, "Knowledge, Attitudes, and Self-Reported Practices of Food Service Staff Regarding Food Hygiene, in Edirne, Tyrkey," Food Control, Vol. 20, No. 8, 2009, pp. 565-568. doi:10.1016/j.foodcont.2008.08.013

[10] E. Walker, C. Pritchard and S. Forsythe, "Hazard Analysis Critical Control Point and Prerequisite Implementation in Small and Medium Size Food Businesses," Food Control, Vol. 14, No. 2, 2003, pp. 169-174. doi:10.1016/S0956-7135(02)00061-0

[11] N. E. Schwartz, "Nutrition Knowledge, Attitude, and Practices of High School Graduates," Journal of American Dietary Association, Vol. 66, No. 1, 1975, pp. 28-31.

[12] M. Howes, S. McEwen, M. Griffiths and L. Harris, "Food Handler Certification by Home Study: Measuring Changes in Knowledge and Behavior," Dairy Food Environment Sanitation, Vol. 16, No. 7, 1996, pp. 737-744.

[13] S. C. Powell, R. W. Attwell and S. J. Massey, "The Impact of Training on Knowledge and Standards of Food Hygiene-A Pilot Study," International Journal of Environment Health Research, Vol. 7, No. 5, 1997, pp. 329334.

[14] D. M. Rennie, "Health Education Models and Food Hygiene Education,” Journal of Royal Social Health, Vol. 115, No. 1, 1995, pp. 75-79.

\section{doi:10.1177/146642409511500203}

[15] J. E. Ehiri, G. P. Morris and J. McEwen, "Evaluation of a Food Hygiene Training Course in Scotland," Food Control, Vol. 8, No. 2, 1997, pp. 137-147. doi:10.1016/S0956-7135(97)00005-4

[16] J. R. Lin and S. Y. Chen, "Study of the Knowledge, Attitudes, and Practices of Food Hygiene by Cooks in Daycare Centers in the Tainan Area," Nutrition Science Journal, Vol. 29, No. 1, 2004, pp. 83-96.

[17] S. Y. Huang, “A Study of F and B Employees' Food Sanitation Knowledge, Attitude and Behavior in Taiwan," Fu Jen Journal of Human Ecology, Vol. 1, No. 1, 1995, pp. 53-71.

[18] S. Y. Lee, J. S. Shieh and C. A. Wen, “An Establishment for the Measurement of Food Safety Practices to Chinese Restaurant Employees," Nutrition Science Journal, Vol. 24, No. 3, 1999, pp. 288-297.

[19] C. J. Griffith and D. Clayton, "Food Safety Knowledge, Attitudes and Practices of Caterers in the UK," In B. Maunsell and D. J. Bolton, Eds., Restaurant and Catering Food Safety, Teagasc, Dublin, Ireland, 2005.

[20] S. Thompson, R. de Burger and O. Kadri, "The Toronto Food Inspection and Disclosure System: A Case Study”. British Food Journal, Vol. 107, No. 2, 2005, pp. 140-149. doi:10.1108/00070700510586461

[21] H. Kassa, “An Outbreak of Norwalk-Like Viral Gastroenteritis in a Frequently Penalized Food Service Operation,” Journal of Environment Health, Vol. 64, No. 10, 2001, pp. 9-13. 